\title{
Evaluation of Clarithromycin Resistance Among Iranian Helicobacter pylori Isolates by E-Test and Real-Time Polymerase Chain Reaction Methods
}

\author{
Mojdeh Hakemi Vala, ${ }^{1,}$ Shirin Eyvazi, ${ }^{2}$ Hossein Goudarzi, ${ }^{1}$ Hamid Reza Sarie, ${ }^{3}$ and Mehrdad Gholami ${ }^{4}$ \\ ${ }^{1}$ Department of Microbiology, Faculty of Medicine, Shahid Beheshti University of Medical Sciences, Tehran, IR Iran \\ ${ }^{2}$ Department of Biotechnology, School of Advanced Technologies in Medicine, Shahid Beheshti University of Medical Sciences, Tehran, IR Iran \\ ${ }^{3}$ Fayazbakhsh Hospital, Tehran, IR Iran \\ ${ }^{4}$ Department of Microbiology, Faculty of Medicine, Iran University of Medical Sciences, Tehran, IR Iran \\ "Corresponding author: Mojdeh Hakemi Vala, Department of Microbiology, Faculty of Medicine, Shahid Beheshti University of Medical Sciences, Tehran, IR Iran. Tel: \\ +98-2123872556, Fax: +98-2122439964, E-mail: m.hakemi@sbmu.ac.ir
}

Received 2015 June 08; Revised 2015 December 20; Accepted 2016 January 24.

\begin{abstract}
Background: Helicobacter pylori is an important pathogen of human gastric mucosa. Antibiotic resistance, especially resistance to clarithromycin is a major factor for treatment failure of $H$. pylori infections. The main mechanism of clarithromycin resistance in these bacteria is related to point mutations in three different locations of $23 \mathrm{~S}$ rRNA gene.

Objectives: The aims of this study were to evaluate the resistance rate to clarithromycin among local $\mathrm{H}$. pylori isolates by the E-test method and to determine the profile of point mutation in $23 \mathrm{~S}$ rRNA by real-time polymerase chain reaction (PCR) method.

Patients and Methods: Eighty biopsy samples were collected from dyspeptic patients by endoscopy during 2011 - 2012. All samples were homogenized immediately and cultured on supplemented brucella blood agar and incubated under microaerophilic conditions. Further biochemical tests and ure C gene PCR was done for $H$. pylori confirmation. The H. pylori OC1096 strain was used as the control strain, simultaneously. Frequency of clarithromycin resistance was determined by the E-test method based on the clinical and laboratory standard institute (CLSI) standards. Point mutation profile was determined by real-time PCR and further analysis of melting curve, amplicon sequencing was done continuously.

Results: From 80 biopsy samples, 20 positive $H$. pylori isolates were detected and confirmed by biochemical tests and PCR method. Overall, $21.7 \%$ of the H. pylori isolates, showed clarithromycin resistance phenotype by use of the E-test. Also, the minimal inhibitory concentration of clarithromycin was determined as $\geq 0.5 \mathrm{mg} / \mathrm{L}$ by the E-test method. Only point mutation in the location of A2143G with melting temperature of $54.7^{\circ} \mathrm{C}$ was observed in all resistant isolates.

Conclusions: This study showed that the frequency of $H$. pylori clarithromycin resistance in Iran is relatively high. Since clarithromycin is not commonly used in Iran for $H$. pylori eradication, the high rate of resistance could be related to cross-reactivity between other macrolides. Therefore, macrolide antibiotics must be prescribed with precaution in any case of treatment other than $H$. pylori infections. All resistant isolates showed A2143G mutation in 23S rRNA as the dominant pattern of point mutation at least in Tehran H. pylori isolates.
\end{abstract}

Keywords: Clarithromycin, Real-Time Polymerase Chain Reaction, Helicobacter pylori

\section{Background}

Helicobacter pylori is a Gram-negative, microaerophilic spiral bacteria that colonize in gastric epithelial tissue and mucus of half of the worlds and $80 \%$ of the Iranian population $(1,2)$. The prevalence of $H$. pylori infection varies all over the world based on geographic area, age, race and sanitary conditions. Helicobacter pylori are mainly acquired in childhood due to lack of proper hygiene (3). Infection with $H$. pylori is associated with some gastrointestinal disorders, including chronic gastritis, peptic ulceration, gastric mucosa-associated lymphoid tissue lymphoma, intestinal metaplasia and gastric cancer (4). Despite the susceptibility of $H$. pylori to many antibiotics in vitro, its eradica- tion is difficult in vivo. This is thought to be due to inactivation of antibiotics in acidic environments of the gastric mucosa (5). Commonly, triple therapy including a proton pump inhibitor (PPI) (omeprazole or pantoprazole) together with two antibiotics such as clarithromycin and metronidazole or amoxicillin is used for treating of $H$. pylori infection. Also, fluoroquinolones, nitrofurans and rifamycins are used as alternatives (6). Clarithromycin has a key role in triple therapy.

Clarithromycin (6-O-methyl erythromycin) is a macrolide antibiotic that inhibits protein synthesis of bacteria by binding to the 50 s subunit of bacterial ribosome. Acid stability and good absorption in gastric 
mucus layer make it a good choice for H. pylori eradication in comparison to other macrolides (7). Unfortunately, appearance and increasing resistance to clarithromycin among $H$. pylori isolates has been reported all over the world (8). This phenomenon decreases the efficacy of $H$. pylori eradication rate, for example in a study, the eradication rate for clarithromycin-susceptible isolates was $90 \%$, whereas it was $36 \%$ for clarithromycin-resistant isolates (9). Also, resistance to clarithromycin shows geographical variation (8). For instance the rate of clarithromycin resistance that was reported in the north of Iran (Sari) is greater than once reported in south (Shiraz) of this country (10). Therefore, before clarithromycin prescription in Helicobacter pylori treatment, determination of the local susceptibility pattern is necessary in any region.

This is possible by approved antibiotic susceptibility testing (AST) methods against bacteria, such as agar dilution, E-test and disk diffusion. Agar dilution is considered as the gold standard method, yet it is highly laborious and expensive. Therefore, agar dilution could be replaced by E-test or disk diffusion methods (11, 12). E-test is a simple and easy test for determining minimal inhibitory concentration (MIC) of a variety of antibiotics, however it is more expensive. Molecular mechanism of clarithromycin resistance in $H$. pylori, is related to point mutations in $23 \mathrm{~S}$ rRNA, which can effect protein synthesis.

The three most popular point mutations in 23S rRNA are A to $G$ transition at position 2142 (A2142G) or 2143 (A2143G) and less frequently, A2142C (13). Several molecular techniques have been developed for the detection of clarithromycin resistance in $H$. pylori including, restriction fragment length polymorphism (RFLP), 3'-mismatch reverse primer PCR method (3M-PCR), PCR-oligonucleotide ligation assay (OLA), fluorescent in situ hybridization (FISH), PCR-preferential homoduplex formation assay (PHFA) and real-time PCR hybridization assay (5). Among these methods, real-time PCR is known as a simple, rapid and reproducible method for the detection of mutations (14). Many investigators used this method for detection of different locations of point mutations in bacterial or eukaryotic genome $(15,16)$. For instance, Oleastro et al. (17) used real-time the PCR assay to detect point mutations in $23 \mathrm{~S}$ rRNA of $H$. pylori and described this method as a rapid, accurate and reliable method for this goal.

\section{Objectives}

The aims of this study were the determination of the resistance rate to clarithromycin among local H. pylori isolates by the E-test method at first and further determination of the point mutation profile by analysis of the melting curve by the real-time PCR method.

\section{Patients and Methods}

\subsection{Patients and Bacterial Strains}

The sample size ( 80 biopsies) was determined based on the frequency of resistance to clarithromycin among H. pylori isolates (28\%) as reported by the study of Malekzadeh et al. (18). Continuously, from patients with gastrointestinal disorders, who were candidates for endoscopy at Milad and Fayyazbakhsh hospitals (Tehran and Karaj, Iran), three biopsies were taken during 2011 - 2012. One of them was used for rapid urease test and the two remaining were transported to microbial laboratory in Stuart's transport medium (Merck, Germany) as soon as possible (less than five hours). Biopsies were homogenized, cultured in selective medium, brucella blood agar (Merck, Germany), including vancomycin (Sigma-Aldrich, USA), trimethoprim sulfametoxazol (Sigma-Aldrich, USA), polymyxin B (SigmaAldrich, USA) antibiotics, supplemented with sodium pyruvate (Sigma-Aldrich, USA) and ferrous sulfate (SigmaAldrich, USA), and then incubated under microaerophilic conditions using the gaspak incubation method (113829 Anaerocult@ A, Merck, Type C Gas-Pak) for 48 - 72 hours at $37^{\circ} \mathrm{C}$. After appearance of colonies, identification tests including Gram staining, catalase and oxidase tests were done. Also, H. pylori isolates were confirmed by PCR amplification of ureC gene after DNA extraction with the boiling method. Primer sequences (Bioneer company, Korea) are showed in Table 1 (17). This research was accepted by the ethics committee of Shahid Beheshti University of Medical Sciences (SBMU) at 13 Jan 2010.

\begin{tabular}{|c|c|c|}
\hline Primer/Probe Name & Sequence & $\begin{array}{c}\text { Hybridization } \\
\text { Region }\end{array}$ \\
\hline \multirow[t]{2}{*}{ ureC (Bioneer, Korea) } & \multicolumn{2}{|c|}{$\begin{array}{l}\text { 5'- } \\
\text { GGATAAGCTTTTAGGGGTGTTAGGGG- } \\
\text { 3' }\end{array}$} \\
\hline & $\begin{array}{l}\text { 5'- } \\
\text { GCTTACTTTCTAACACTAAC } \\
3^{\prime}\end{array}$ & \\
\hline \multirow[t]{2}{*}{$\begin{array}{l}\text { HPY-S, HPY-A } \\
\text { (Bioneer, Korea) }\end{array}$} & $\begin{array}{l}\text { 5'- } \\
\text { AGGTTAAGAGGATGCGTCAGTC- } \\
\text { 3' }\end{array}$ & \\
\hline & $\begin{array}{l}\text { 5'- } \\
\text { CGCATGATATTCCCATTAGC } \\
\text { 3' }\end{array}$ & \\
\hline \multirow[t]{2}{*}{$\begin{array}{l}\text { Sensor probe, Anchor } \\
\text { probe (Bioneer, } \\
\text { Korea) }\end{array}$} & $\begin{array}{l}\text { 5'Cy5- } \\
\text { GGCAAGACGGAAAGACC- } \\
\text { 3' }\end{array}$ & $2504-2520$ \\
\hline & $\begin{array}{l}\text { TGTAGTGGAGGTGAAAATT' } \\
\text { 3'FAM }\end{array}$ & $2473-2501$ \\
\hline
\end{tabular}




\subsection{Antibiotic Susceptibility Test}

Resistance to clarithromycin was tested with epsilometer strips (E-test, Lioflichem Co, Denmark), according to the CLSI protocol and manufacturer's instructions. Fresh $H$. pylori isolates were subcultured on selective brucella blood agar (Merck, Germany) for 72 hours. Bacterial suspension equivalent to McFarland turbidity standard three were prepared and spread on non-selective brucella blood agar plates (without antibiotics). After drying of plates, a single E-test strip was placed on them. The plates were incubated under microaerophilic conditions (116275/Anaerocult $®$ C Merck, Germany) at $37^{\circ} \mathrm{C}$. After 72 hours, susceptibility and MIC of the isolates were determined, simultaneously. The H. pylori OC1096 strain (bestowed by research center for gastroenterology and hepatology disease, Shahid Beheshti University of Medical Sciences Tehran, Iran) was used as a control isolate. The sensitive $(S)$ and resistant $(R)$ isolates were determined based on the MIC as follow; $S \leq 0.25 \mathrm{mg} / \mathrm{L}$ and $\mathrm{R} \geq 0.5 \mathrm{mg} / \mathrm{L}$.

\subsection{DNA Extraction}

DNA extraction was done by the boiling method (19, 20). The concentration of extracted DNA was determined after optical density (OD) detection by the nanodrop instrument (Biointellectic TM Nano 200, Canada).

\subsection{UreC Amplification}

For confirmation of detected colonies as H. pylori, existence of ureC gene was done by the PCR method. The PCR reaction was carried out in a thermal cycler (Eppendorph Master cycle, Germany) as follow; 35 amplification cycles consisting of a denaturation step at $94^{\circ} \mathrm{C}$ for one minute, an annealing step at $54^{\circ} \mathrm{C}$ for one minute and extension step at $72^{\circ} \mathrm{C}$ for one minute, which were performed after a pre-denaturation of the target DNA at $94^{\circ} \mathrm{C}$ for four minutes. The final cycle was an extension step at $72^{\circ} \mathrm{C}$ for five minutes.

3.5. Detection of 23S rRNA Gene Mutations of H. pylori by RealTime-Polymerase Chain Reaction

The molecular mechanism of clarithromycin resistance was investigated by the real time-PCR method and determination of the melting temperature. Real-time PCR was performed on DNA extracted from $H$. pylori isolates in Rotor-Gene 6,000 (Corbett). A primer pair (HPY-S and HPYA, Table 1) was used to amplify the $267 \mathrm{bp}$ fragment of $23 \mathrm{~s}$ RNA gene. Also, sensor and anchor probes were used to determine point mutations. Real-time PCR assays were performed as follows: an initial denaturation step at $95^{\circ} \mathrm{C}$ for
10 minutes, followed by 50 cycles with a temperature transition rate of $20^{\circ} \mathrm{C} /$ second, consisting of $95^{\circ} \mathrm{C} /$ second, annealing at $60^{\circ} \mathrm{C}$ for 10 seconds, and extension at $72^{\circ} \mathrm{C}$ for 17 seconds. After amplification, a melting step was carried out: $95^{\circ} \mathrm{C} /$ second, cooling to $45^{\circ} \mathrm{C}$ for 30 seconds with a temperature transition rate of $20^{\circ} \mathrm{C} /$ second, and finally a slow heating to $85^{\circ} \mathrm{C}$ at a rate of $0.1^{\circ} \mathrm{C} /$ second with continuous acquisition of fluorescence decline. Further sequencing of six H. pylori isolates (four resistant, one sensitive and a control strain) was done by the Bioneer Company, Korea.

\section{Results}

After culture of 80 biopsies, $20 \mathrm{H}$. pylori strains were isolated (25\%). All biochemical tests including Gram staining, catalase and oxidase tests confirmed $H$. pylori isolates. Also, the presence of ureC gene in all 20 isolates was confirmed by PCR (Figure 1). Resistance to clarithromycin was observed in 4 of $20 \mathrm{H}$. pylori isolates (21.7\%) according to the CLSI standards and by the E-test method. Resistant isolates had MIC of $>0.5 \mathrm{mg} / \mathrm{mL}$ (Figure 2). The type of mutation in clarithromycin resistance isolates was determined by realtime PCR. According to Figure 3 melting temperature of probes in susceptible isolates and H. pylori OC1096 strain, was $57.5^{\circ} \mathrm{C}$, but in resistance isolates this was $54.7^{\circ} \mathrm{C}$. Also, as mentioned before for confirmation of the real-time PCR results, sequencing was done on PCR products of six isolates in parallel. All resistant isolates in this study showed a point mutation at $\mathrm{A} 2143 \mathrm{G}$ based on the detected melting temperature and sequencing. Two sequences of amplicons were submitted to NCBI with accession No KP09939 and KP09939.1.

\section{Figure 1. PCR Amplification Performed With ureC Primers}

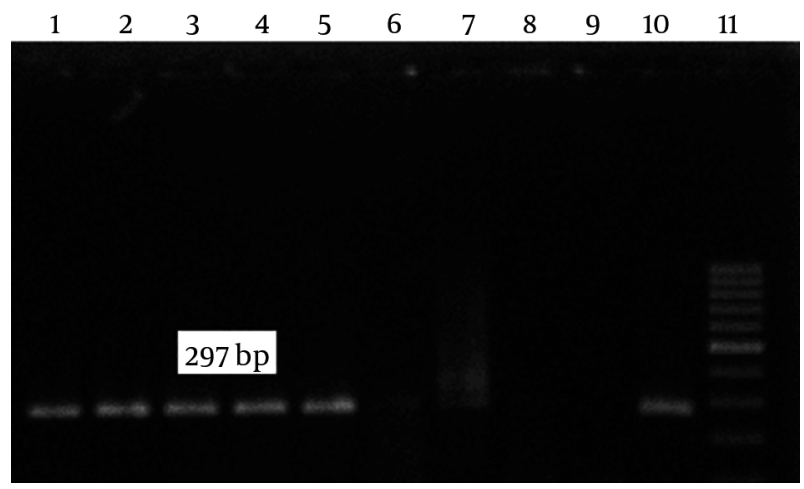

H. pylori isolates (lanes 1-9), negative control (lane 10), positive control (lane 11) and ladder (Qiagen). 


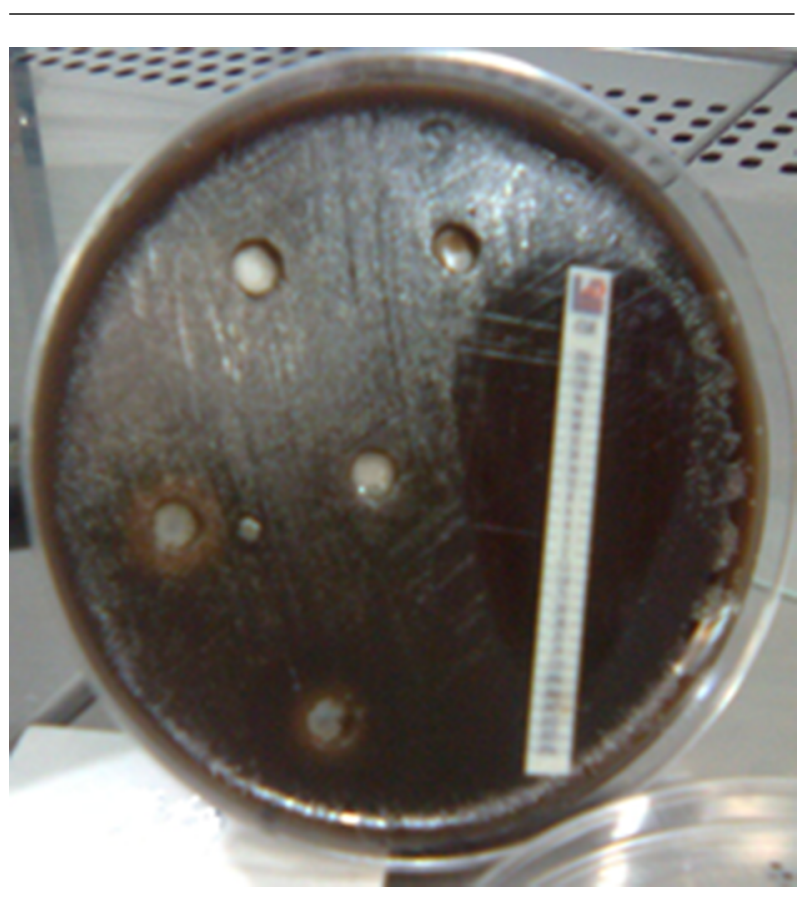

Figure 2. Antibiogram of Helicobacter pylori Isolates by the E-Test Method

\section{Discussion}

Helicobacter pylori, is a major cause of upper gastrointestinal disorders such as peptic and duodenal ulcers and gastric cancer. About half of the world's population is infected with $H$. pylori (1). One of the best antibiotics that are used in first line therapy for this infection is clarithromycin.

Clarithromycin is a macrolide antibiotic that inhibits protein synthesis of bacteria by binding to the 50 second subunit of bacterial ribosome and preventing of peptidyl transferase activity (21). However, emerging and spreading of antibiotic resistance, especially resistance to clarithromycin, decreases the efficacy of $H$. pylori infection treatment (22). Therefore, detection of the local antibiotic resistance profile is important. In our study we used the E-test method for determination of resistance to clarithromycin among $H$. pylori isolates.

Clarithromycin resistance was observed in four of 20 H. pylori isolates (21.7\%). Because of high precision and reproducibility of E-test results, we used this method in our study. Similar to our results, the rate of clarithromycin resistance that had been reported by Ogata et al. (23) from Brazil and De Francesco et al. (24) from Italy by the E-test method, was about $22.62 \%$ and $18.49 \%$, respectively. However, the rates of clarithromycin resistance that have been described by other studies (by the E-test method) were
Figure 3. Details of Melting Curve

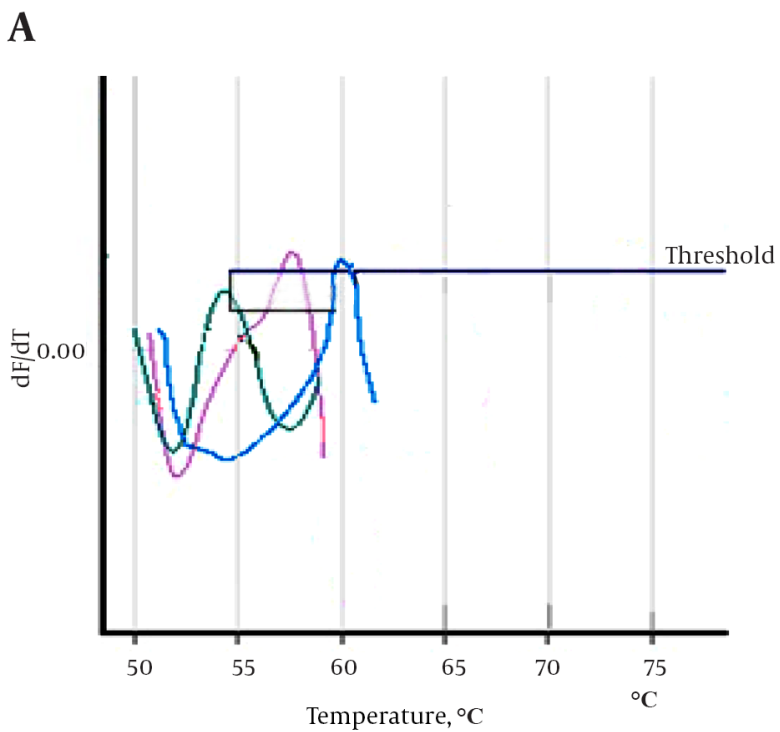

\section{B}

\begin{tabular}{|l|l|l|}
\hline Color & Genotype & Peak \\
\hline & $\begin{array}{l}\text { H. pylori control with point mutation } \\
\text { of A2142C }\end{array}$ & $57.5^{\circ} \mathrm{C}$ \\
\hline & $\begin{array}{l}\text { Clarithromycin Resistant with } \\
\text { point mutation of A2143G }\end{array}$ & $54.7^{\circ} \mathrm{C}$ \\
\hline & $\begin{array}{l}\text { Clarithromycin Sensitive } \\
\text { With no point mutation }\end{array}$ & $61^{\circ} \mathrm{C}$ \\
\hline
\end{tabular}

A, Melting Curve shows the different melting temperatures of the 267-bp amplicon of the 23SrRNAof the control, sensitiveandresistant isolates of $H$. pylori in this study; $\mathrm{B}$, details of the diagram.

different. For instance, it was $41.9 \%$ in Turkey (25), 35.6\% in Spain (26), 5.3\% in Costa Rica (27) and 10.6\% in Taiwan (28). Existence of such differences is logical, because antibiotic susceptibility profile shows geographical variation between and within countries based on age, race, population density and availability of antibiotics (29). Such discrepancies exist between studies from different parts of Iran. For example, Sirous et al. (30) reported that all $H$. pylori strains isolated from Iran were sensitive to clarithromycin (by the disk diffusion method). Also, clarithromycin resis- 
tance rate among $H$. pylori isolates in Tehran (by the disk diffusion method) and Southern Iran (Shiraz, by the E-test method) was inconsiderable (4.16\% and 5\%, respectively) $(31,32)$. However, other Iranian studies showed considerable rate of clarithromycin resistance among $H$. pylori isolates e.g. $16 \%$ and $17.7 \%$ in north west of Iran (Tabriz, by the E-test and modified disk diffusion method) (33,34), 30\% in the north (Sari, by the E-test method) (35), 32\% in the west (Ilam, by the disk diffusion method) (36) and 32.4\% in Tehran (by the agar dilution method) (37).

The difference between the rates of clarithromycin resistance in studies, which have been done in different parts of Iran may be due to time differences, use of different susceptibility methods, sample sizes, fresh or freeze biopsies and incubation conditions. Over all, this study and other studies that reported high rate of resistance to clarithromycin among $H$. pylori isolates, showed that clarithromycin resistance rate has reached alarming rates in our country, Iran. Clarithromycin is an expensive antibiotic and not commonly used in Iran, so these rates of resistance could be related to cross-reactivity with other macrolides. For example, Fallahi and Maleknejad (31) reported that the rate of resistance to erythromycin (other kinds of macrolide antibiotics) among H. pylori strains is $4.16 \%$, which is equal to clarithromycin resistance rates.

Resistance to clarithromycin in H. pylori is caused by point mutations at different locations or different base substitutions of $23 \mathrm{~S}$ rRNA. The most common mutations are A2143G and A2142G, and less frequently A2142C (13). The A2142G and A2142C mutations are associated with highlevel cross-resistance to all macrolides; also the A2143G mutation is linked to high-level resistance to erythromycin (38). In this study, we used the real-time PCR method to determine the type of mutation in resistant isolates. First, the 267-bp fragment of 23S rRNA was amplified by Corbett 6,000 , and then the mutation was determined by melting curve analysis. According to the melting curve Figure 3, the melting temperature of all resistant $H$. pylori isolates was at $54.7^{\circ} \mathrm{C}$. Therefore, all resistant $H$. pylori isolates had the $\mathrm{A} 2143 \mathrm{G}$ mutation. Also, sequencing results confirmed A2143G mutation. The melting temperature of susceptible and $0 C 1096$ strain, were $61^{\circ} \mathrm{C}$ and $57.5^{\circ} \mathrm{C}$, respectively. Oleastro et al. (17) used the Light thermo cycler apparatus and reported that the melting temperature of susceptible, standard and resistance (A2143G mutation) isolates were $61.5^{\circ} \mathrm{C}, 58^{\circ} \mathrm{C}$ and $53.6^{\circ} \mathrm{C}$, respectively.

The inconsiderable difference to our results $\left(57.6^{\circ} \mathrm{C}\right)$ may be due to the use of different instruments and standard strains. Sadeghifard et al. (36) investigated mutations of $23 \mathrm{~S}$ rRNA gene among $H$. pylori isolates by the PCR-restriction fragment length polymorphism (RFLP) method. In that study, all resistant isolates had the A2143G mutation. Also, in a study performed by Kargar et al. (39) using PCR-RFLP, mutation of A2143G was the dominant point mutation among $H$. pylori isolates. Mohammadi et al. (40) used the PCR-RFLP method and reported $73.68 \%$ of $H$. pylori isolates had the A2143G mutation. All mentioned studies reported similar point mutations among Iranian $H$. pylori strains despite the use of different methods. Therefore, it seems that the frequency of A2143G mutation among clarithromycin resistant $H$. pylori isolates from Iranian patients is higher than other mutations. Similar results were observed in clarithromycin-resistant $H$. pylori strains isolated from Korea (by PCR amplification and nucleotide sequence analyses) (41), Argentina (by PCR-RFLP method) (42) and Colombia (by the PCR-RFLP method) (43). However, other kinds of point mutations of clarithromycin resistance were shown in other studies from Iran. For example, the incidence of A2142G genotype in the study of Naserpour Farivar et al. (44), by scorpion real-time PCR, was higher than other mutations. Also, in the study of Khademi et al. (45) all clarithromycin-resistant H. pylori isolates had the T2243C mutation by PCR and further sequencing methods.

In conclusion, our results and other studies in Iran, despite some controversial results, showed that the rate of clarithromycin resistance is increasing in our country. Also it seems the most popular pattern of clarithromycin resistance among Iranian $H$. pylori isolates is the A2143G mutation. Also determination of the antibiotic resistance profile and finding alternative treatment regimens in any region of the world is necessary. Finally, real-time PCR is a rapid and reproducible method for detecting mutations in $23 \mathrm{~S}$ rRNA of $H$. pylori isolates. For better evaluation of clarithromycin resistance rate and finding the predominant molecular pattern of resistance among Iranian H.pylori isolates, doing such study with a greater sample size is recommended.

\section{Acknowledgments}

The authors are thankful to the staff of the endoscopy department of Milad and Fayyazbakhsh hospitals for their kind cooperation.

\section{Footnotes}

Authors' Contribution: The core idea of this work came from Mojdeh Hakemi Vala and Hossein Goudarzi, who were the advisors of this project and contributed to the analysis of the data. Hamid Reza Sarie performed the endoscopy and prepared the gastric biopsies. Mehrdad Gholami and Shirin Eyvazi collected and cultured the biopsy 
samples, and performed the molecular tests and also wrote the manuscript in collaboration with Mojdeh Hakemi Vala.

Funding/Support: A grant was awarded by the Shahid Beheshti University of Medical Sciences, Tehran, IR Iran.

\section{References}

1. Kusters JG, van Vliet AH, Kuipers EJ. Pathogenesis of Helicobacter pylori infection. Clin Microbiol Rev. 2006;19(3):449-90. doi: 10.1128/CMR.00054-05. [PubMed: 16847081].

2. Alborzi A, Soltani J, Pourabbas B, Oboodi B, Haghighat M, Hayati $\mathrm{M}$, et al. Prevalence of Helicobacter pylori infection in children (south of Iran). Diagn Microbiol Infect Dis. 2006;54(4):259-61. doi: 10.1016/j.diagmicrobio.2005.10.012. [PubMed: 16466888].

3. Brown LM. Helicobacter pylori: epidemiology and routes of transmission. Epidemiol Rev. 2000;22(2):283-97. [PubMed: 11218379].

4. McColl KE. Clinical practice. Helicobacter pylori infection. $N$ Engl J Med. 2010;362(17):1597-604. doi: 10.1056/NEJMcp1001110. [PubMed: 20427808].

5. Gerrits MM. Erasmus MC:University Medical Center Rotterdam;2004. Molecular mechanisms of antibiotic resistance in Helicobacter pylori.

6. Gisbert JP. Rescue Therapy for Helicobacter pylori Infection 2012. Gastroenterol Res Pract. 2012;2012:974594. doi: 10.1155/2012/974594. [PubMed: 22536225].

7. Lee JH, Shin JH, Roe IH, Sohn SG, Lee JH, Kang GH, et al. Impact of clarithromycin resistance on eradication of Helicobacter pylori in infected adults. Antimicrob Agents Chemother. 2005;49(4):1600-3. doi: 10.1128/AAC.49.4.1600-1603.2005. [PubMed: 15793150].

8. De Francesco V, Giorgio F, Hassan C, Manes G, Vannella L, Panella C, et al. Worldwide H. pylori antibiotic resistance: a systematic review. J Gastrointestin Liver Dis. 2010;19(4):409-14. [PubMed: 21188333].

9. Houben $\mathrm{MH}$, van de Beek D, Hensen EF, de Craen AJ, et al. A systematic review of Helicobacter pylori eradication therapy-the impact of antimicrobial resistance on eradication rates. Aliment Pharmacol Ther. 1999;13(8):1047-55. [PubMed: 10468680]

10. Eyvazi S, Hakemi-Vala M. A Review Article on Helicobacter pylori Antibiotic Resistance Profile in Iran. Int J Trop Dis Health. 2015;10(1):1-12.

11. Yu C, Li L, Chen W, Jiao Y, Yang N, Yang E, et al. Levofloxacin susceptibility testing for Helicobacter pylori in China: comparison of E-test and disk diffusion method. Helicobacter. 2011;16(2):119-23. doi: 10.1111/j.1523-5378.2011.00820.x. [PubMed: 21435089].

12. Mishra KK, Srivastava S, Garg A, Ayyagari A. Antibiotic susceptibility of Helicobacter pylori clinical isolates: comparative evaluation of diskdiffusion and E-test methods. Curr Microbiol. 2006;53(4):329-34. doi: 10.1007/s00284-006-0143-1. [PubMed: 16972131].

13. van Doorn LJ, Glupczynski Y, Kusters JG, Megraud F, Midolo P, MaggiSolca N, et al. Accurate prediction of macrolide resistance in Helicobacter pylori by a PCR line probe assay for detection of mutations in the 23S rRNA gene: multicenter validation study. Antimicrob Agents Chemother. 2001;45(5):1500-4. doi: 10.1128/AAC.45.5.1500-1504.2001. [PubMed: 11302817].

14. Morlan J, Baker J, Sinicropi D. Mutation detection by real-time PCR: a simple, robust and highly selective method. PLoS One. 2009;4(2):ee4584. doi: 10.1371/journal.pone.0004584. [PubMed: 19240792].

15. Bernard PS, Wittwer CT. Real-time PCR technology for cancer diagnostics. Clin Chem. 2002;48(8):1178-85. [PubMed: 12142370].

16. McCulloch E, Lucas C, Ramage G, Williams C. Improved early diagnosis of Pseudomonas aeruginosa by real-time PCR to prevent chronic colonisation in a paediatric cystic fibrosis population. J Cyst Fibros. 2011;10(1):21-4. doi:10.1016/j.jcf.2010.09.001. [PubMed: 20920896].

17. Oleastro M, Menard A, Santos A, Lamouliatte H, Monteiro L, Barthelemy P, et al. Real-time PCR assay for rapid and accurate de- tection of point mutations conferring resistance to clarithromycin in Helicobacter pylori. J Clin Microbiol. 2003;41(1):397-402. [PubMed: 12517879].

18. Malekzadeh R, Mohamadnejad M, Siavoshi F, Massarrat S. Treatment of Helicobacter pylori infection in Iran: low efficacy of recommended western regimens. Arch Iranian Med. 2004;7(1):1-8.

19. Holmes DS, Quigley M. A rapid boiling method for the preparation of bacterial plasmids. Anal Biochem. 1981;114(1):193-7. [PubMed 6269464].

20. Queipo-Ortuno MI, De Dios Colmenero J, Macias M, Bravo MJ, Morata P. Preparation of bacterial DNA template by boiling and effect of immunoglobulin $\mathrm{G}$ as an inhibitor in real-time PCR for serum samples from patients with brucellosis. Clin Vaccine Immunol. 2008;15(2):2936. doi: 10.1128/CVI.00270-07. [PubMed:18077622].

21. Kanoh S, Rubin BK. Mechanisms of action and clinical application of macrolides as immunomodulatory medications. Clin Microbiol Rev. 2010;23(3):590-615. doi: 10.1128/CMR.00078-09. [PubMed: 20610825].

22. Megraud $F$. The challenge of Helicobacter pylori resistance to antibiotics: the comeback of bismuth-based quadruple therapy. Therap Adv Gastroenterol. 2012;5(2):103-9. doi:10.1177/1756283X11432492. [PubMed 22423259].

23. Ogata SK, Gales AC, Kawakami E. Antimicrobial susceptibility testing for Helicobacter pylori isolates from Brazilian children and adolescents: comparing agar dilution, E-test, and disk diffusion. Braz J Microbiol. 2014;45(4):1439-48. [PubMed: 25763052].

24. De Francesco V, Zullo A, Ierardi E, Giorgio F, Perna F, Hassan C, et al. Phenotypic and genotypic Helicobacter pylori clarithromycin resistance and therapeutic outcome: benefits and limits. J Antimicrob Chemother. 2010;65(2):327-32. doi: 10.1093/jac/dkp445. [PubMed: 20008044].

25. Bakir OS, Ozakin C, Keskin M. [Antibiotic resistance rates of Helicobacter pylori isolates and the comparison of E-test and fluorescent in situ hybridization methods for the detection of clarithromycin resistant strains]. Microbiol bulteni. 2009;43(2):227-34.

26. Agudo S, Perez-Perez G, Alarcon T, Lopez-Brea M. High prevalence of clarithromycin-resistant Helicobacter pylori strains and risk factors associated with resistance in Madrid, Spain. J Clin Microbiol. 2010;48(10):3703-7. doi:10.1128/JCM.00144-10. [PubMed: 20668128].

27. Lang L, Garcia F. Comparison of E-test and disk diffusion assay to evaluate resistance of Helicobacter pylori isolates to amoxicillin, clarithromycin, metronidazole and tetracycline in Costa Rica. Int J Antimicrob Agents. 2004;24(6):572-7. doi: 10.1016/j.ijantimicag.2004.07.009. [PubMed: 15555880].

28. Chang WL, Sheu BS, Cheng HC, Yang YJ, Yang HB, Wu JJ. Resistance to metronidazole, clarithromycin and levofloxacin of Helicobacter pylori before and after clarithromycin-based therapy in Taiwan. J Gastroenterol Hepatol. 2009;24(7):1230-5. doi: 10.1111/j.14401746.2009.05829.x. [PubMed: 19476562].

29. Gahbauer AM, Gonzales ML, Guglielmo BJ. Patterns of antibacterial use and impact of age, race/ethnicity, and geographic region on an tibacterial use in an outpatient medicaid cohort. Pharmacotherapy. 2014;34(7):677-85. doi: 10.1002/phar.1425. [PubMed: 24753176]

30. Sirous M, Mehrabadi JF, Daryani NE, Eshraghi S, Hajikhani S, Shirazi MH. Prevalence of antimicrobial resistance in Helicobacter pylori isolates from Iran. Afr J Biotechnol. 2013;9(36).

31. Fallahi GH, Maleknejad S. Helicobacter pylori culture and antimicrobial resistance in Iran. Indian J Pediatr. 2007;74(2):127-30. [PubMed 17337822].

32. Farshad S, Alborzi A, Japoni A, Ranjbar R, Hosseini Asl K, Badiee P et al. Antimicrobial susceptibility of Helicobacter pylori strains isolated from patients in Shiraz, Southern Iran. World J Gastroenterol 2010;16(45):5746-51. [PubMed: 21128326].

33. Rafeey M, Ghotaslou R, Nikvash S, Hafez AA. Primary resistance in Helicobacter pylori isolated in children from Iran. I Infect Chemother 2007;13(5):291-5. doi: 10.1007/s10156-007-0543-6. [PubMed: 17982716]. 
34. Ghotaslou R, Milani M, Akhi MT, Hejazi MS, Nahaei MR, Hasani A, et al. Relationship between drug resistance and cagA Gene in Helicobacter pylori.JundishapurJMicrobiol. 2013;6(10):e8480. doi:10.5812/jjm.8480.

35. Talebi Bezmin Abadi A, Mobarez AM, Taghvaei T, Wolfram L. Antibiotic resistance of Helicobacter pylori in Mazandaran, North of Iran Helicobacter. 2010;15(6):505-9. doi: 10.1111/j.1523-5378.2010.00795.x. [PubMed: 21073606].

36. Sadeghifard N, Seidnazari T, Ghafourian S, Soleimani M, Maleki A, Qomi MA, et al. Survey in Iran of clarithromycin resistance in Helicobacter pylori isolates by PCR-RFLP. Southeast Asian J Trop Med Public Health. 2013;44(1):89-95. [PubMed: 23682442].

37. Shokrzadeh L, Alebouyeh M, Mirzaei T, Farzi N, Zali MR. Prevalence of multiple drug-resistant Helicobacter pylori strains among patients with different gastric disorders in Iran. Microb Drug Resist. 2015;21(1):105-10. doi:10.1089/mdr.2014.0081. [PubMed: 25303151].

38. Garcia-Arata MI, Baquero F, de Rafael L, Martin de Argila C, Gisbert $\mathrm{JP}$, Bermejo F, et al. Mutations in 23S rRNA in Helicobacter pylori conferring resistance to erythromycin do not always confer resistance to clarithromycin. Antimicrob Agents Chemother. 1999;43(2):3746. [PubMed: 9925537].

39. Kargar M, Baghernejad M, Doosti A, Ghorbani-Dalini S. Clarithromycin resistance and 23S rRNA mutations in Helicobacter pylori isolates in Iran. Afr J Microbiol Res. 2011;5(8):853-6.

40. Mohammadi M, Doroud D, Mohajerani N, Massarrat S. Helicobacter pylori antibiotic resistance in Iran. World J Gastroenterol. 2005;11(38):6009-13. [PubMed: 16273615].
41. Kim JM, Kim JS, Kim N, Kim YJ, Kim IY, Chee YJ, et al. Gene mutations of $23 \mathrm{~S}$ rRNA associated with clarithromycin resistance in Helicobacter pylori strains isolated from Korean patients.J Microbiol Biotechnol. 2008;18(9):1584-9. [PubMed:18852516].

42. Alarcon T, Vega AE, Domingo D, Martinez MJ, Lopez-Brea M. Clarithromycin resistance among Helicobacter pylori strains isolated from children: prevalence and study of mechanism of resistance by PCR-restriction fragment length polymorphism analysis. J Clin Microbiol. 2003;41(1):486-99. [PubMed: 12517902].

43. Alvarez A, Moncayo JI, Santacruz JJ, Santacoloma M, Corredor LF, Reinosa E. Antimicrobial susceptibility and mutations involved in clarithromycin resistance in Helicobacter pylori isolates from patients in the western central region of Colombia. Antimicrob Agents Chemother. 2009;53(9):4022-4. doi: 10.1128/AAC.00145-09. [PubMed: 19546360].

44. Naserpour Farivar T, Najafipour R, Johari P. Prevalence of clarithromycin-resistant Helicobacter pylori in patients with chronic tonsillitis by allele-specific Scorpion real-time polymerase chain reaction assay. Laryngoscope. 2013;123(6):1478-82. doi: 10.1002/lary.23777. [PubMed: 23404672].

45. Khademi F, Faghri J, Moghim S, Esfahani BN, Fazeli H, Poursina F, et al. The study of mutation in $23 \mathrm{~S}$ rRNA resistance gene of Helicobacter pylori to clarithromycin in patients with gastrointestinal disorders in Isfahan - Iran. Adv Biomed Res. 2014;3:98. doi: 10.4103/2277-9175.129368. [PubMed: 24800187]. 